\title{
The availability and effectiveness of reported mediators in associative learning: A historical review and an experimental investigation
}

\author{
JOHN T. E. RICHARDSON \\ Brunel University, Uxbridge, England
}

\begin{abstract}
This paper provides a historical review and empirical investigation of the availability and the effectiveness of different types of mediator in associative learning, as inferred from subjects' retrospective reports. Mental imagery is a preferred mediational strategy in the learning of pairs of common concrete nouns, and its use is associated with a high level of recall performance. Its availability and its effectiveness are both enhanced if subjects are given interactive imagery instructions. It is argued that retrospective mediator reports provide valid accounts of the cognitive processes that occur at the time of learning and that play a causal role in determining the subsequent level of retention.
\end{abstract}

A fundamental notion in memory research over the last 40 years is the idea that people engage in cognitive processing that determines how well the information in question is remembered. These cognitive activities are generally thought to be under strategic control and available to conscious awareness. It follows that they can be manipulated by giving instructions to experimental subjects to set about learning in different ways, and that they can be studied by asking people to describe how they have in fact set about particular learning tasks. These latter accounts are of interest in their own right and also provide a means of checking whether subjects have actually complied with instructions to use different learning strategies.

One of the earliest studies to collect such accounts was described by Reed (1918a, 1918b). He asked 27 subjects to learn four sets of paired associates: two sets consisted of unrelated pairs of English words, the third set consisted of German words paired with their English translations, and the fourth set contained pairs of consonant-vowelconsonant (CVC) nonsense syllables. (The subjects were apparently not familiar with German.) When the subjects were asked how they had tried to remember the pairs of words, they tended to report associative aids based on shared semantic features or on linking images or phrases; however, in the case of the other sets, they were more likely to report the use of linking English words that were phonemically similar to the pair as a whole.

A preliminary account of the findings contained in this paper was presented at the 2nd International Conference on Memory, which was held at Abano Terme, Italy, July 14-19, 1996. This paper was written while the author was a Visiting Research Professor in the Institute of Educational Technology at the Open University. He is grateful to John Gardiner, Alison Green, Lowell Groninger, Michael Gruneberg, Marc Marschark, and Siné McDougall for their comments and suggestions. Correspondence should be addressed to J. T. E. Richardson, Department of Human Sciences, Brunel University, Uxbridge, Middlesex UB8 3PH, England (e-mail: john.richardson@brunel.ac.uk).
Reed (1918a) noted that every subject reported some paired associates that had been learned with the use of associative aids and others that had been learned "mechanically, i.e., without association" (p. 133). He then demonstrated that, on each set of paired associates, reports of associative aids were correlated with better recall during the original learning phase and with superior retention in a retest carried out the following day. He inferred that these findings established a causal relationship between the use of associative aids and the rates of learning and forgetting. These results demonstrate some key points that lie at the heart of contemporary theoretical discussions concerning memory and memory improvement.

In particular, effective learning depends on the deployment of active encoding operations that involve the manipulation or elaboration of mental representations of the information to be remembered (Herrmann \& Searleman, 1990). In practice, however, people deploy encoding operations that they perceive to be appropriate to the properties of the stimulus material and the particular demands of the learning task (Craik \& Lockhart, 1972). In associativelearning tasks, for instance, people are likely to use aids or mediators that serve to link together the items to be remembered. These encoding operations constitute control processes that can be the object of conscious reflection and the subject of verbal report (Bellezza, 1986).

Recent accounts of the basic principles underlying human learning and memory tend not to refer explicitly to the idea of associative mediation, but they take it for granted that performance depends on mental structures and processing activities (see, e.g., Crowder, 1993; Kihlstrom, 1996). It is certainly assumed that the use of associative mediators can be promoted by appropriate instructions and can bring about increased levels of recall performance (e.g., Murdock, 1997). It is less clear, however, whether mediators of different types vary in their effectiveness and whether their effectiveness varies in turn under different instructional sets. 
A vast amount of research has been carried out since the 1960s into the efficacy of spontaneously occurring strategies, as well as more formal mnemonic systems. However, these studies have usually operationalized the use of associative mediators in terms of the administration of particular instructional sets and their effectiveness in terms of the resulting level of performance (e.g., Roediger, 1980). Consequently, they have confounded the effectiveness of associative mediators with their availability. To address these issues, it is necessary to obtain separate evidence on the availability of different types of associative mediator, and this can be achieved through the collection of verbal reports.

In this paper, I describe the historical development of this kind of research, and I conclude that the limited amount of empirical evidence on these issues is wholly unconvincing, simply because previous studies have involved idiosyncratic samples of material and small samples of subjects. Consequently, although nowadays the issues in question are widely regarded as having long been settled, this is not in fact the case. I report a new experiment carried out to evaluate the availability and the effectiveness of different kinds of mediator in supporting associative learning. This new experiment was designed to remedy the defects in earlier studies by collecting data from a very large sample of subjects and by showing that the findings generalized beyond the specific materials that were used.

\section{NATURAL LANGUAGE MEDIATORS IN VERBAL LEARNING}

More than 40 years after the publication of Reed's articles, work by several researchers confirmed his main findings that associative aids were commonly reported in verbal-learning tasks and that pairs learned with the use of associative aids were remembered better than pairs learned without their assistance. As Underwood (1964) concluded, "there are reportable and measurable counterparts of the theoretical notions of mediation" (p. 69). The studies in question involved paired associates consisting of letters and numbers (L. L. Clark, Lansford, \& Dallenbach, 1960), random letter trigrams and common three-letter words (Underwood \& Schulz, 1960, pp. 296305), pairs of CVC nonsense syllables (Bugelski, 1962; Dean \& R. B. Martin, 1966), or CVC nonsense syllables and words (Dallett, 1964; Kiess \& Montague, 1965; R. B. Martin \& Dean, 1964). No very systematic analysis of the associative aids or mediating links was attempted in any of these studies, but the examples cited were typically single words or short phrases based on phonological cues, letter identities, semantic relations, or personal experiences.

C. J. Martin, Boersma, and Cox (1965) classified reports that were given by subjects learning pairs of disyllabic nonwords. They identified five categories of asso- ciative devices (linking phrases or sentences, common features, embedded words, multiple-letter cues, and singleletter cues), together with repetition (or rote rehearsal) and no reported association. C. J. Martin, Boersma, and Cox had used a forced-choice recognition procedure to evaluate retention, and they found that the number of correct responses made during the learning of each pair was directly related to the apparent complexity of the corresponding reported cue or mediational strategy. In particular, recognition performance was best with associative mediators, intermediate with repetition, and poorest when no association at all had been reported.

C. J. Martin, Cox, and Boersma (1965) showed that the apparent complexity of reported mediators according to this classification scheme was greater for pairs consisting of items of high associative meaningfulness (common disyllabic nouns) than for pairs consisting of items of low associative meaningfulness (rare disyllabic nouns and disyllabic nonwords). Similarly, Montague, Adams, and Kiess (1966) showed that associative mediators were more likely to be reported for pairs of CVCs of high-rated meaningfulness (many of which were genuine words) than for pairs of CVCs of low-rated meaningfulness. Montague and Wearing (1967) replicated the findings of C. J. Martin, Boersma, and Cox (1965) when subjects learned pairs containing CVC nonsense syllables and words, except that the vast majority of reports in their study referred to associative mediators based on common features or linking phrases or sentences or referred simply to rote repetition. In fact, in studies that used pairs of words (e.g., pairs of adjectives), the reported mediators consisted chiefly of simple sentences linking the stimulus and response terms (Adams \& Montague, 1967; Runquist \& Farley, 1964). These findings were regarded as evidence for the importance of natural language mediation in verbal learning (Montague et al., 1966; Prytulak, 1971).

In addition, other researchers demonstrated that improved performance in paired-associate learning would be obtained if simple linking sentences were provided by the experimenter, and that even greater improvement would result if the subjects were instructed to make up the sentences themselves (e.g., Bobrow \& Bower, 1969; Bower \& Winzenz, 1970; Jensen \& Rohwer, 1963; Rohwer, 1966). Even instructions to think of a single word connecting the words in a pair lead to improved recall performance (Bellezza \& Poplawsky, 1974). In addition, the reported use of verbal mediators is increased when subjects are explicitly provided with appropriate mediators and when they are instructed to create mediators for themselves (Schwartz, 1969; Wood \& Bolt, 1968). Wood and Bolt were able to demonstrate that the improvement resulting from the provision of verbal mediators did not simply reflect an increase in the subjects' level of motivation but depended on the specific relations between the mediators and the items to which they were attached. 
In other words, these manipulations serve to enhance recall performance by selectively increasing the availability of effective mnemonic devices.

\section{MENTAL IMAGERY AS A MEDIATING DEVICE}

Nevertheless, in retrospect, the predominance of verbal mediators in these early studies seems to have been due mainly to the use of relatively abstract materials. Paivio, Yuille, and Smythe (1966) collected mediator reports following the presentation of a list of paired associates for four learning trials. The materials were nouns selected in order to manipulate imageability, concreteness, and meaningfulness, and the subjects were asked to report whether they had tried to learn each paired associate by using a verbal mediator, by making up a mental image connecting the two words, or without using any such device. Verbal mediators were reported for merely $15 \%$ of concrete pairs of high imageability, but for $40 \%$ of abstract pairs of low imageability. Conversely, imaginal mediators were reported for $59 \%$ of concrete pairs of high imageability, but for only $19 \%$ of abstract pairs of low imageability. Similar results were obtained by Paivio, Smythe, and Yuille (1968) and by Richardson (1978).

As well as studying the availability of mediators of different types, measured by the unconditional probability that mediators of any particular type would be reported, Paivio et al. (1966) assessed the effectiveness of mediators of different types, measured by the conditional probability that the response term in a paired associate would be correctly recalled, given that a mediator of a particular type had been reported. In agreement with previous research, pairs for which mediators were reported were more likely to be remembered than were pairs for which mediators were not reported. Both imaginal mediators and verbal mediators appeared to be more effective when learning concrete pairs than when learning abstract pairs. Moreover, imaginal mediators seemed to be more effective than verbal mediators, but only when learning concrete pairs, not when learning abstract pairs.

These findings encouraged Paivio and Yuille (1967) to obtain mediator reports in another experiment in which subjects were specifically asked to use verbal mediators, mental imagery, or rote repetition in order to learn materials varying in either imageability or meaningfulness. Subsequently, the subjects were asked to report whether they had in fact tried to learn each pair by repetition, verbal mediation, imaginal mediation, some other device, or no such strategy. The subjects who had been instructed to use verbal mediators or mental imagery achieved higher recall scores than did the subjects who had been instructed to use rote repetition. In addition, an analysis of their mediator reports showed that these varied among the three groups in accordance with their different instructional sets.

However, Paivio and Yuille (1967) found that the distribution of reported mediators was determined more by the attributes of the pairs to be learned than by the particular instructional set under which the material had been learned. For instance, the subjects who had received imagery instructions reported that they had in fact used imaginal mediators for $82 \%$ of pairs of high imageability, but for only $28 \%$ of pairs of low imageability. Similar results were subsequently obtained by Yuille and Paivio (1968), Yarmey and Csapo (1968), and Paivio and Yuille (1969). Moreover, in the latter study, Paivio and Yuille (1969) found that imaginal mediators (and, to some extent, verbal mediators) were reported more often over successive learning trials, regardless of the instructional set.

As Paivio (1971, p. 362) later commented, these results demonstrated that subjects' associative strategies are only partly controlled by their experimental instructions and may often be determined more by the semantic properties of the materials to be remembered. This notion was examined in detail by McDaniel and Kearney (1984), who asked their subjects to perform three different verbal-learning tasks under various instructional sets and then asked them to describe how often they had used different strategies. McDaniel and Kearney found that the most efficient strategy varied from task to task and that uninstructed subjects tended spontaneously to use the most efficient strategy or strategies for each specific learning task.

McDaniel and Kearney (1984) argued that the efficacy of encoding strategies depended on whether they promoted the encoding of requisite information that was not spontaneously activated by the material itself. For example, when learning pairs of words drawn from the same taxonomic category, their preexisting associations would tend to prompt a semantic encoding strategy whatever the experimental instructions. This was confirmed in a study by McDougall and Velmans (1993), who found that, regardless of instructional set, imaginal mediators were usually reported when learning pairs of words whose referents usually occurred in spatial contiguity (e.g., flagmast), whereas verbal mediators were usually reported when learning pairs of words drawn from the same taxonomic category (e.g., potato-spinach).

\section{THE EFFECTIVENESS OF VERBAL AND IMAGINAL MEDIATORS}

Paivio and his colleagues originally tried to explain the increased performance that results from administering imagery instructions in terms of the enhanced availability of mental imagery as a distinct mnemonic code (see Paivio, 1969). Indeed, a few studies found that imagery instructions (either alone or in combination with verbal mediation instructions) led to a greater increase in recall than did verbal instructions alone (Bower, 1972: Bower \& Winzenz, 1970; Rimm, Alexander. \& Eiles, 1969). Nevertheless, most studies found no significant difference between imagery instructions and verbal mediation instructions with regard to the resulting improvement 
(Hulicka \& Grossman, 1967; Janssen, 1976b, 1976c; Paivio \& Yuille, 1967; Wood, 1967; Yarmey \& Csapo, 1968; Yuille \& Paivio, 1968). This led some researchers to infer that imaginal and verbal mediators simply encouraged relational organization within a single code or system (Anderson \& Bower, 1973, p. 457; Begg, 1978; Rohwer, 1973).

However, as the findings obtained by Paivio and Yuille (1967) showed, it cannot be assumed that the appropriate form of mnemonic processing will automatically be induced by instructions to subjects to use mental imagery or verbal mediation. To address this issue, Paivio and Foth (1970) forced their subjects to externalize their mental images and verbal mediators as drawn pictures and written phrases or sentences in the 15-sec presentation interval. Under these circumstances, they found that, for concrete pairs, imagery instructions led to better recall performance than did verbal instructions, but, for abstract pairs, led to poorer recall performance than did verbal instructions. Paivio and Foth also recorded the times taken to begin drawing a picture or to begin writing a phrase or sentence: They found no difference in the response latencies on concrete pairs, but they found longer latencies for pictures than for verbal mediators on abstract pairs.

Paivio and Foth (1970) argued that the poorer performance on abstract pairs under imagery instructions could be attributed to the reduced availability of imaginal mediators. Indeed, on average, their subjects had been unable to generate an imaginal mediator for $27 \%$ of abstract pairs within the time limit of $15 \mathrm{sec}$. Using a similar procedure but self-paced presentation, Yuille (1973) confirmed that imaginal mediators required longer to produce than did verbal mediators for abstract pairs, but he found that subsequent recall was not significantly different between the two instructional sets. This supports the view that, for abstract pairs, imaginal and verbal mediators differ in their availability, but that they do not differ in their effectiveness once they have become available.

According to Paivio and Foth's (1970) response latency data, there seemed to be no difference between the availability of imaginal and verbal mediators in the case of concrete pairs. This suggested that the better performance obtained on concrete pairs under imagery instructions should be attributed to the greater effectiveness of imaginal mediators in learning such pairs. Yuille (1973) confirmed that imaginal mediators were discovered as quickly as verbal mediators in the case of concrete pairs. However, he found that imaginal mediators gave rise to superior recall than verbal mediators only when subjects were tested after a 1 -week delay. With immediate testing, there was no significant difference between performance using imaginal and verbal mediators, regardless of the concreteness of the materials.

Nevertheless, the procedure adopted by Paivio and Foth (1970) is vulnerable to the criticism that it confounds the effects of instructing subjects to think up a mental image or verbal mediator with the effects of instructing them to draw a picture or to write down a phrase or sentence (see Janssen, 1976b, 1976c). It is known, for example, that perceptual images stored in short-term visual memory are functionally different from images generated by the manipulation of discrete components retrieved from long-term memory (see Kosslyn, 1994, pp. 102-104). Since the subjects who were instructed to use mental imagery were also instructed to provide themselves with a pictorial presentation of the material to be recalled, it is in principle impossible to determine which of these constituted the effective mnemonic device. It is also conceivable that subjects in such experiments generate drawings to comply with their instructions even when they have failed to come up with a relevant image, in which case the drawn picture would be a substitute for an imaginal mediator rather than its visible counterpart.

It can indeed be argued that self-reports provide the only logically adequate basis for ascribing mental imagery and other cognitive activities (see Richardson, 1980, pp. 34-35). Consequently, postexperimental probes designed to obtain subjects' reports of the mediators that they have used in a specific verbal-learning task are an indispensable tool in evaluating which associative devices are employed by subjects under standard learning instructions or whether particular groups of subjects actually comply with different instructional sets (McDaniel, 1988; cf. also Anderson \& Kulhavy, 1972; Eagle, 1967; Hasher, Riebman, \& Wren, 1976). The failure of certain subjects to comply with their strategic instructions has also been noted in experiments on sentence-picture verification (Marquer \& Pereira, 1990). This led Ericsson and Simon (1993, p. lii) to argue that, in any sort of cognitive research, it was essential to obtain some form of verbal report to assess the strategies adopted by individual subjects.

Similarly, the question of whether mediators of different types vary in their effectiveness needs to be addressed by evaluating the conditional probability of correct recall, given that mediators of different types have been reported. As mentioned above, Paivio et al. (1966) originally found that, in the absence of any specific instructions, imaginal mediators were significantly more effective on this definition than were verbal mediators, but only when learning concrete material, not when learning abstract material. A similar, although less clear-cut, pattern was obtained by Paivio, Smythe, and Yuille (1968), but they did not attempt a statistical analysis of these data. In two different studies, Hulicka and Grossman (1967) and Hulicka, Sterns, and Grossman (1967) found that imaginal mediators were more effective than verbal mediators for older adults but not for high-school students; again, no statistical analysis was conducted on these data. Finally, in two further experiments, McDougall and Velmans (1993) found no significant differences in the effectiveness of imaginal and verbal mediators in the case of 
either categorically or spatially related pairs, although, in each case, imaginal mediators tended to be more effective than verbal mediators.

A separate question is whether imaginal mediators are more effective when subjects have been explicitly instructed to use mental imagery than when they have not been given any specific instructional set. Although it does not seem to be a formal implication of his dual-coding theory, Paivio (1971, p. 359) held that imagery mnemonic instructions act to enhance the availability of imaginal mediators but not their effectiveness (see also Janssen, 1976a, p. 15). Richardson (1985) evaluated this idea using both concrete and abstract pairs and using both a betweensubjects manipulation and a within-subjects manipulation of the instructional set. He found no significant difference in the effectiveness of imaginal mediators between imagery instructions and standard instructions. Nevertheless, imaginal mediators tended to be more effective under imagery instructions for both concrete and abstract pairs and using both a between-subjects manipulation and a within-subjects manipulation of the instructional set.

On both these issues, then, there is a paucity of empirical evidence, and the evidence that is available is neither convincing nor consistent. On the one hand, the studies that found variations in the effectiveness of different mediators involved short paired-associate lists, and, hence, they might have been detecting spurious phenomena associated with idiosyncratic samples of words. On the other hand, the studies that failed to generate significant effects involved small samples of subjects, and, thus, they will have been lacking in statistical power. In the following experiment, the effectiveness of different mediators was evaluated in a very large sample of subjects under both standard instructions and imagery instructions, and appropriate statistical techniques were used to ensure that the findings generalized beyond the particular pairs of nouns that were actually used.

\section{METHOD}

\section{Subjects}

This study involved students taking degrees in psychology, sociology, and social anthropology on a first-year undergraduate course in research methods, at which regular attendance was a formal course requirement. The experiment was repeated exactly with 8 successive cohorts of students, so that data were obtained from a total of 515 students ( 144 men, and 371 women). Their ages ranged from 17 years to 69 years, but $80 \%$ were between 17 and 27 years of age, and their average age was 23.4 years. In each cohort, students signed up to take this course during either the morning (typically, between 10:00 a.m. and 12:00 noon) or the afternoon (typically, between 2:00 p.m. and 4:00 p.m.) of the same day of each week, depending on their academic and nonacademic commitments. In total, 286 attended the morning sessions and 229 attended the afternoon sessions. A further group of 31 students who were attending for interview in seeking admission to the same degrees provided normative rating data on the stimulus materials.

\section{Materials}

To promote the use of a variety of associative devices, the materials consisted of common concrete nouns. Common nouns were defined as those with a frequency of $\mathrm{AA}$ or $\mathrm{A}$ in the norms published by Thorndike and Lorge (1944) (i.e., at least 50 occurrences per million words). Concrete nouns were defined as those with concreteness and imagery ratings of more than 6.30 in the norms published by Paivio, Yuille, and Madigan (1968). This yields a total of 90 common concrete nouns, although the norms of Paivio, Yuille, and Madigan (p. 3) contain only a "semirandom" subset of 272 out of more than 400 nouns with a frequency of AA or A in the norms of Thorndike and Lorge. This implies that there exist more than 130 common concrete nouns in the entire English language. Eighty items were sampled strictly at random from the total of 90 common concrete nouns identified in this way. These words were assigned at random to two lists of 20 pairs (List $A$ and List $B$ ), and these are shown in the Appendix. Each list can be regarded as a random sample drawn from the entire population of more than $130 \times 129$, or 16,770 possible pairs of common concrete nouns. Five other pairs of nouns with a frequency of AA or A were added to the beginning and end of each list as filler items in order to remove any primacy and recency effects in recall.

\section{Procedure}

Each half of each cohort was tested as a single group under normal classroom conditions. The students who attended in the morning session were tested on List A followed by List $\mathrm{B}$, and the students who attended in the afternoon session were tested on List $B$ followed by List A.

For the first list, the subjects were given standard paired-associate learning instructions that made no mention of any mnemonic techniques. They were simply asked to remember that the word on the left of each pair appeared with the word on the right, so that later, if shown the word that appeared on the left of a pair, they would be able to remember the word that had appeared with it on the right. The list of 30 pairs was then presented on slides at a rate of $10 \mathrm{sec} /$ pair. Immediately afterwards, the subjects were given a prepared response sheet that contained the stimulus terms from the 20 critical pairs in a new random order and were asked to write by each the corresponding response term. They were allowed $3 \mathrm{~min}$ for their recall.

The subjects then received a postlearning questionnaire that listed the 20 critical paired associates in their original order of presentation. For each pair, they were asked to indicate the type of mediator that they had used in learning that pair (i.e., "imagery," "verbal," "repetition," "other," or "none"), regardless of whether they had in fact remembered that pair. The instructions followed those of previous studies (Paivio, Smythe, \& Yuille, 1968; Richardson, 1985). and they included examples of the different types of mediator. If the subjects had used more than one mediator, they were instructed to indicate the type that seemed to be the most important. Finally, they were asked to ensure that they indicated one and only one of the five types of mediator for each of the 20 pairs of words.

For the second list, the subjects received additional instructions to make up mental images relating together the words within each pair. The specific instructions were as follows (following Richardson, 1985):

Experiments have in fact shown that a useful way to try and remember pairs of words is to make up mental images which relate together the two words in each pair. I am now going to show you another 30 pairs of words which I would like you to try and remember, and this time I would like you specifically to try to make up such images in learning these pairs of words.

In other respects, the presentation, the testing, and the collection of mediator reports proceeded exactly as for the first list, except that 
it was explained that the purpose of the postlearning questionnaire was to determine whether or not the subjects had actually been able to use mental imagery to learn each of the pairs of words.

Finally, the subjects were asked to write their names on each of the response sheets and each of the postlearning questionnaires so that these could subsequently be collated, but they were assured that their results would not be used in any way in connection with their academic assessment and that no individual would be identified in any account of the research.

Normative data were collected on the imageability and relatedness of each pair of nouns. The instructions for imageability ratings were taken from Richardson's (1979) Experiment 2; these asked the subjects to rate the ease with which each pair aroused a mental image in which the two things were interrelated or interacting in some way, using a scale ranging from 1 (low imagery) to 7 (high imagery). The instructions for relatedness ratings were adapted from Marschark and Hunt's (1989) Experiment 5; these asked the subjects to rate the extent to which the pairs of words were related or associated to one another, using a scale ranging from 1 (unrelated) to 7 (highly related). Questionnaires with these two sets of instructions were distributed alternately among the 31 available subjects. Three of the subjects who were asked to give ratings on relatedness failed to do so for all 40 pairs of words. As a result, complete data were available from 16 subjects who rated their imageability but from only 12 subjects who rated their relatedness.

\section{RESULTS}

Taking subjects as the random factor and pooling data over 20 pairs in each of the two lists, this experiment had a mixed design that involved the between-subjects variable of sessions (i.e., morning vs. afternoon) and the withinsubjects variable of instructions (standard vs. imagery). Taking pairs as the random factor and pooling data over the subjects attending each of the two sessions, this experiment had a mixed design that involved the betweenpairs variable of lists (List A vs. List B) and the withinpairs variable of sessions (morning vs. afternoon). In the latter design, the effect of instructions could be identified with the lists $\times$ sessions interaction.

Analyses of variance (ANOVAs) based on these designs enable one to compute separate values of $F$ that can be combined into a single statistic min $F^{\prime}$ using procedures described by H. H. Clark (1973). This enables one to evaluate experimental hypotheses taking both subjects and pairs as random factors, so that the findings generalize beyond the sample of materials used here. None of the analyses produced either a significant main effect of sessions or a significant interaction between the effect of sessions and the effect of instructions. This is of some interest insofar as it suggests that the results were not contaminated by time-of-day effects, but the account that follows will be concerned solely with the effect of instructions.

\section{Correct Recall}

The 515 subjects recalled $56.5 \%$ of the pairs that they had learned under standard instructions, but they recalled $73.8 \%$ of the pairs that they had learned under imagery instructions. The difference between these figures was highly significant $\left[\min F^{\prime}(1,84)=118.24, p<.001\right]$.

\section{Mediator Availability}

Out of 20,600 responses to the postlearning questionnaires, one and only one mediator was reported in 20,282 (or $98.5 \%$ ) of cases. In general, the subjects appeared to have little difficulty in carrying out this task.

Nevertheless, 46 (or $8.9 \%$ ) of the 515 subjects failed to indicate at least one mediator for every pair, and these omissions accounted for 154 responses. In most cases, these were apparently isolated and inadvertent omissions. However, 8 subjects failed to indicate mediators for more than 3 pairs in either one list or both lists, and this usually seemed to be due to their misunderstanding the task to demand responses only in the case of pairs that had been correctly recalled. The inclusion of these subjects would have produced biased estimates of the availability and the effectiveness of different mediators, and so the data of these 8 subjects were dropped from the subsequent analysis of mediator reports.

In addition, 51 (or $9.9 \%$ ) of the 515 subjects indicated more than one mediator for at least 1 pair, and these "ambiguous" responses accounted for 164 responses. These were considered too few for detailed examination and were therefore ignored in the subsequent analysis of mediator reports. Again, these were in most cases isolated or occasional responses. However, 4 subjects produced ambiguous responses for more than $50 \%$ of the pairs in one list or both lists, and the data of these subjects also were dropped from the analysis of mediator reports. Usable data concerning the availability and effectiveness of mediators of different types were therefore available from 503 of the original 515 subjects.

Table 1 summarizes the availability of mediators of each type under standard instructions and imagery instructions, defined as the probability that each type was reported in each of the postlearning questionnaires (calculated over all pairs for which one and only one mediator had been reported). These means are logically dependent, in that the means within each column add to unity, and so separate tests were conducted on each mediator type. The subjects were more likely to report imaginal mediators under imagery instructions than under standard instructions [ $\left.\min F^{\prime}(1,140)=328.74, p<.001\right]$. However, they were less likely to report verbal mediators

Table 1

Mean Availability and Effectiveness of Different Mediators Under Standard Instructions and Imagery Instructions

\begin{tabular}{lccccc}
\hline & \multicolumn{2}{c}{ Availability } & & \multicolumn{2}{c}{ Effectiveness } \\
\cline { 2 - 3 } \cline { 5 - 6 } Mediator & Standard & Imagery & & Standard & Imagery \\
\hline Imagery & .53 & .84 & & .70 & .79 \\
Verbal & .16 & .07 & & .64 & .67 \\
Repetition & .14 & .02 & & .39 & .44 \\
Other & .05 & .02 & & .61 & .67 \\
None & .12 & .05 & & .08 & .06 \\
\hline
\end{tabular}

Note-Availability was defined as the (unconditional) probability that mediators of each type were reported in the postlearning questionnaires. Effectiveness was defined as the (conditional) probability that an item was correctly recalled, given that mediators of each type were reported. 
$\left[\min F^{\prime}(1,277)=97.69\right]$, repetition $\left[\min F^{\prime}(1,204)=\right.$ 111.05], other mediators [ $\min F^{\prime}(1,327)=32.58$ ], or no mediators at all $\left[\mathrm{min} F^{\prime}(1,208)=56.29\right]$ under imagery instructions than under standard instructions (all $p \mathrm{~s}<.001)$.

The availability of different mediators under standard instructions was compared with the rated imageability and relatedness of the 40 pairs of words. The ratings on both scales were distributed across all seven response categories with overall means of 4.42 on imageability and 3.10 on relatedness (the mean ratings of each pair of nouns are shown in the Appendix). The mean ratings on imageability varied between 2.81 and 6.38 , and they were less than 4.00 for 18 (or $45 \%$ ) of the pairs; in other words, while the constituent words themselves were concrete and highly imageable, nearly half of the pairs were rated as being relatively hard to image. The mean ratings on relatedness varied between 1.25 and 6.42 , and they were less than 4.00 for 32 (or $80 \%$ ) of the pairs; in other words, the majority of pairs were rated as being relatively unrelated. Across all 40 pairs of nouns, imageability and relatedness were highly correlated $(r=+.81)$, which supports a suggestion made by Paivio, J. M. Clark, and Khan (1988) that the availability of imaginal mediators is greater for pairs of words whose meanings are somehow related (see also Morris \& Reid, 1975). There was no difference between List A and List B on either scale $\left(F_{\mathrm{s}}<1\right)$.

Table 2 shows the partial correlation coefficients between mediator availability and rated imageability, controlling for the effects of rated relatedness, and the partial correlation coefficients between mediator availability and rated relatedness, controlling for the effects of rated imageability. Under standard instructions, imaginal mediators tended to be reported for items of high imageability, verbal mediators tended to be reported for items of high relatedness and low imageability, and repetition and no mediators tended to be reported for items of low relatedness and low imageability, whereas reports of other mediators were unrelated to both the imageability and the relatedness of the pairs in question.

\section{Mediator Effectiveness}

The effectiveness of mediators of each type was defined as the conditional probability of correct recall,

Table 2

Partial Correlations Between Ratings of the Imageability and Relatedness of Paired Associates and the Availability of Different Mediators

\begin{tabular}{lcc}
\hline Mediator & Imageability & Relatedness \\
\hline Imagery & $+.56_{+}^{+}$ & -.07 \\
Verbal & $-.35^{*}$ & $+.52^{+}$ \\
Repetition & $-.41^{\dagger}$ & $-.35^{*}$ \\
Other & $-.16^{*}$ & +.09 \\
None & $-.33^{*}$ & $-.36^{*}$ \\
\hline
\end{tabular}

Note-Availability was defined as the (unconditional) probability that mediators of each type were reported in the postlearning questionnaires under standard instructions. ${ }^{*} p<.05 . \quad{ }^{+} p<.01 . \quad{ }^{+} p<.001$. (Twotailed tests used in each case.) given that a mediator of a particular type had been reported. (The "effectiveness" of no mediators was defined as the conditional probability of correct recall, given that no mediator had been reported.) This was analyzed separately for standard instructions and imagery instructions. For the subjects analyses, the effectiveness of each mediator was estimated for each subject by dividing the number of correctly recalled pairs for which that mediator had been reported by the total number of pairs for which that mediator had been reported. For the pairs analyses, the effectiveness of each mediator was estimated for each pair by dividing the number of subjects who reported the mediator in question and who also correctly recalled that pair by the total number of subjects who reported that mediator. As before, the values of $F$ that resulted from these separate analyses were combined into $\min F^{\prime}$ statistics using the procedures described by H. H. Clark (1973). These remain valid even if the separate analyses are conducted on different data (Coleman, 1979).

Table 1 displays mean estimates obtained from the subjects analysis of the effectiveness of mediators of each type under standard instructions and under imagery instructions. These estimates are logically independent of one another, but each is based on only the subjects who reported the relevant mediator for at least one pair. Only 3 subjects reported the use of all five mediators in learning both lists; 48 subjects reported all five mediators in learning the first list, and 7 subjects reported all five mediators in learning the second list. Therefore, separate analyses were carried out on the data from the first list and on the data obtained for particular mediators from both lists.

In the case of the 48 subjects who reported all five mediators when learning the first list, there was a significant effect of mediator type $\left[\min F^{\prime}(4,211)=18.49, p<\right.$ $.001]$. This legitimated the use of a series of tests to contrast the effectiveness of each possible pair of mediator types, using data from all the subjects who reported both mediators when learning the first list. These tests showed that every type of mediator was significantly different from every other, with the sole exception that there was no difference between the effectiveness of verbal mediators and the effectiveness of other mediators $\left[\min F^{\prime}(1,148)=\right.$ $1.24, p>.25]$. In particular, imaginal mediators were more effective than verbal mediators $\left[\min F^{\prime}(1,305)=\right.$ $5.58, p<.02]$, other mediators were more effective than repetition $\left[\min F^{\prime}(1,123)=13.50, p<.001\right]$, and repetition was more effective than no mediators $\left[\min F^{\prime}(1,134)=\right.$ $51.52, p<.001]$.

In the case of the 481 subjects who reported imaginal mediators when learning both lists, the effectiveness of imaginal mediators was greater under imagery instructions than under standard instructions $\left[\mathrm{min} F^{\prime}(1,78)=\right.$ $23.05, p<.001]$. However, there was no effect of instructions upon the effectiveness of verbal mediators [min $\left.F^{\prime}(1,193)=1.20, p>.25\right]$, repetition $\left[\min F^{\prime}(1,110)=\right.$ $0.07, p>.70]$, other mediators $\left[\min F^{\prime}(1,68)=0.20, p>\right.$ $.60]$, or no mediators $\left[\min F^{\prime}(1,144)=0.51, p>.40\right]$. 


\section{Compliance With Instructions}

The finding mentioned above that the subjects in this experiment were more likely to report imaginal mediators under imagery instructions than under standard instructions suggests that they had generally complied with their instructions. Indeed, 421 (or $83.7 \%$ ) of the 503 subjects who had provided usable data reported more imaginal mediators when learning the second list than when learning the first list. Another 54 (or 10.7\%) of the subjects reported the same number of imaginal mediators in learning the two lists; 43 of these subjects were already at ceiling, in that they reported the exclusive use of imaginal mediators on both lists, whereas the remaining 11 subjects reported the same number of imaginal mediators in learning the two lists, even though they could have reported more when learning the second list. Finally, 28 (or $5.6 \%$ ) of the subjects reported fewer imaginal mediators in learning the second list than in learning the first list.

Table 3 shows the recall performance of these four groups of subjects under standard instructions and under imagery instructions. ANOVAs by subjects and items produced significant effects of groups $\left[\min F^{\prime}(3,608)=\right.$ $11.35, p<.001]$ and instructions $\left[\min F^{\prime}(1,214)=\right.$ $10.66, p<.005]$, and a significant interaction [min $\left.F^{\prime}(3,382)=5.66, p<.001\right]$. A posteriori tests showed that the simple main effect of instructions was significant for the "compliers" group $\left[\min F^{\prime}(1,201)=50.93, p<\right.$ $.001]$, and the "ceilings" group $\left[\min F^{\prime}(1,556)=3.92\right.$, $p<.05]$, but not for the "constants" group $\left[\min F^{\prime}(1,495)\right.$ $=0.00, p>90]$ or the "noncompliers" group [min $\left.F^{\prime}(1,573)=0.62, p>.40\right]$.

Table 3 shows that the two groups who did not exhibit an increase in the use of imaginal mediators under imagery instructions but who could in principle have done so also did not show an increase in the proportion of pairs that were correctly recalled. Nevertheless, it might be noted that none of the groups showed a decline in performance under these conditions and that all of the groups were performing at a high level throughout. In addition, the groups who did not show an increase in their use of imaginal mediators under imagery instructions reported a far higher spontaneous use of imaginal mediators under standard learning instructions. Of course, in this case, the dependent variable (the reported use of imaginal mediators) was used to define the membership of the four groups, and it would not be appropriate to carry out any statistical analysis on these data.

Table 3 shows the effectiveness of imaginal mediators for these four groups under standard instructions and imagery instructions. ANOVAs by subjects and items produced significant main effects of groups $\left[\min F^{\prime}(3,583)=\right.$ $3.69, p<.02]$ and instructions $\left[\min F^{\prime}(1,196)=10.83\right.$, $p<.005]$, but no sign of any interaction $\left[\min F^{\prime}(3,568)=\right.$ $0.10, p>.95]$. In other words, the effectiveness of imaginal mediators was systematically different, depending on whether the subjects complied with instructions to use mental imagery, but the reasons for this are unclear. More importantly, however, the effectiveness of imaginal mediators was significantly greater under imagery instructions than under siandard instructions, and the size of this increase was essentially the same in all four groups of subjects.

\section{DISCUSSION}

This study has generated evidence concerning the availability and the effectiveness of five different techniques or strategies that are used in associative learning. These represent the entire range of categories that are used by independent judges when they classify open-ended descriptions produced by subjects of the associative strategies that they have employed in associative-learning tasks (Yuille \& Paivio, 1968). It will be helpful to discuss each of these in turn.

\section{Imaginal Mediators}

This study found that, in the paired-associate learning of noun pairs, mental imagery was reported as a mediational device more than $50 \%$ of the time, even when the

Table 3

Mean Probability of Correct Recall and Mean Availability and Effectiveness of Imaginal Mediators Under Standard Instructions and Imagery Instructions

\begin{tabular}{|c|c|c|c|c|c|c|}
\hline \multirow[b]{2}{*}{ Group } & \multicolumn{2}{|c|}{ Correct Recall } & \multicolumn{2}{|c|}{ Availability } & \multicolumn{2}{|c|}{ Effectiveness } \\
\hline & Standard & Imagery & Standard & Imagery & Standard & Imagery \\
\hline Compliers & .54 & .73 & .46 & .84 & .69 & .78 \\
\hline Ceilings & .78 & .86 & 1.00 & 1.00 & .78 & .86 \\
\hline Constants & .77 & .79 & .68 & .68 & .81 & .91 \\
\hline Noncompliers & .68 & .72 & .81 & .67 & .73 & .84 \\
\hline
\end{tabular}

Note-Compliers ( $n=421$ ) were more likely to report imaginal mediators under imagery instructions than under standard instructions. Ceilings $(n=43)$ reported only imaginal mediators under both standard and imagery instructions. Constants $(n=11)$ were equally likely to report imaginal mediators under both standard and imagery instructions, but they were not at a ceiling. Noncompliers $(n=28)$ were more likely to report imaginal mediators under standard instructions than under imagery instructions. Availabilit. was defined as the probability that imaginal mediators were reported in the postlearning questionnaires. Effectiveness was defined as the conditional probability that an item was correctly recalled, given that imaginal mediators were reported. 
subjects were given experimental instructions that did not mention any particular learning strategy. Moreover, the reported use of mental imagery was associated with a high level of recall performance. These results confirm the implications of previous studies that imagery is a preferred and effective mediational strategy in the associative learning of pairs of common concrete nouns on the part of mature learners (McDaniel \& Kearney, 1984; Paivio, Smythe, \& Yuille, 1968; Paivio et al., 1966; Richardson, 1978, 1985).

Nevertheless, it should also be pointed out that the availability of imaginal mediators varied within the samples of material employed in this experiment. Not surprisingly, imaginal mediators were more likely to be reported on pairs of nouns that other subjects rated as highly imageable, in the sense that they easily aroused mental images in which the things described by the two words were interrelated or interacting in some way. The four pairs that produced the highest proportions of imaginal mediators under standard instructions were hospitalwindow $(78 \%)$, village-forest $(72 \%)$, chair-garden $(67 \%)$, and gold-tower $(66 \%)$.

Imaginal mediators proved to be more effective than any of the other techniques or strategies that were identified in this experiment, even in the absence of explicit instructions. In particular, the effectiveness of reported imagery was significantly greater than that of verbal mediators. This confirms the findings that were obtained by Paivio et al. (1966) when subjects learned concrete material, as well as nonsignificant trends that are apparent in both of the experiments reported by McDougall and Velmans (1993). It also confirms the similar conclusions drawn by Paivio and Foth (1970), without adopting the questionable strategy of forcing the subjects to externalize their mediators in the form of drawn pictures or written phrases or sentences. These findings are consistent with the dual-coding view that mental imagery provides access to a separate and more efficient representational system, but they are equally consistent with the notion that mental imagery simply brings about efficient encoding and retrieval within a single representational system (cf. Marschark \& Cornoldi, 1991; Marschark, Richman, Yuille, \& Hunt, 1987; Rohwer, 1973).

This experiment has also confirmed that instructions to use imaginal mediators in associative-learning tasks produce a substantial increase in the reported use of imaginal mediators and substantial improvements in the amount recalled. Because imaginal mediators are more effective than other techniques, part of the increase in performance that results from imagery instructions can be attributed to the increased availability of effective associative devices. Nevertheless, the present experiment also found that instructions to use imaginal mediators gave rise to a highly significant and selective increase in the effectiveness of the imaginal mediators that were actually employed. In other words, there is an additional component that results from the enhanced effectiveness of imaginal mediators under explicit imagery instructions.
This study used a within-subjects manipulation of the instructional set, and, in principle, it is possible that the latter result was confounded with practice or carryover effects. However, Richardson (1985) obtained (nonsignificant) effects of similar magnitude using both betweensubjects and within-subjects manipulations of the instructional set. Consequently, it is unlikely that the increased effectiveness of imaginal mediators in learning the second list in this experiment was somehow the result of the subjects' experience of using mental images to learn the first list. An alternative explanation is that spontaneously created mental images are sometimes poorly structured and that explicit imagery instructions tend to promote the sort of interactive encoding that is known to facilitate associative learning (see Bower, 1970).

Although the vast majority of the subjects complied with instructions in that they were more likely to report the use of imaginal mediators with imagery instructions than with standard instructions, 39 subjects (or $7.8 \%$ of the total) did not show an increase in their use of imaginal mediators, even though they could in principle have done so. The failure of certain subjects to comply with imagery instructions in verbal-learning tasks has been noted informally by some other researchers (M. M. Gruneberg, personal communication, July 16, 1996; Persensky \& Senter, 1970), but this has not been formally investigated to date. These subjects showed no increase in their absolute level of recall performance. However, they did exhibit an increase in the effectiveness of imaginal mediators of the same magnitude as that shown by the remaining subjects, and, to that extent, they too could be said to have responded to the instructional set in an appropriate way.

\section{Verbal Mediators}

This study found that, in the paired-associate learning of noun pairs, verbal mediators were reported as a mediational device only one sixth of the time when the subjects were given instructions that did not specify any particular learning strategy. This is consistent with the results of previous studies using randomly assigned pairs of common concrete words (Paivio, Smythe, \& Yuille, 1968; Paivio et al., 1966; Richardson, 1978; but cf. McDaniel \& Kearney, 1984). Verbal mediators are more frequently reported when learning pairs containing abstract nouns (Paivio et al., 1966; Richardson, 1978), other parts of speech (Adams \& Montague, 1967; Runquist \& Farley, 1964), or meaningless materials (Bugelski, 1962; L. L. Clark et al., 1960; Dallett, 1964; Dean \& R. B. Martin, 1966; Kiess \& Montague, 1965; C. J. Martin, Boersma, \& Cox, 1965; R. B. Martin \& Dean, 1964; Montague \& Wearing, 1967; Underwood \& Schulz, 1960).

Again, however, the availability of verbal mediators varied within the samples of material employed in this experiment. Verbal mediators were more likely to be reported on pairs of nouns that other subjects rated as being highly related or associated to one another, but also as less imageable, in the sense that they did not easily arouse images in which the things described by the two words 
were interacting in some way. The four pairs of words that produced the highest proportion of verbal mediators under standard instructions were child-diamond ( $28 \%)$, sea-lake ( $28 \%)$, sugar-body $(25 \%)$, and coffee-mountain $(23 \%)$.

Not surprisingly, verbal mediators were reported even less often when the subjects had been given instructions to use mental imagery. Nevertheless, with both standard instructions and imagery instructions, verbal mediators seemed to be almost (though not quite) as effective as imaginal mediators in ensuring correct recall. The high level of performance associated with verbal mediators is consistent with the findings obtained by C. J. Martin, Boersma, and Cox (1965) and Montague and Wearing (1967), and it tends to confirm the value of natural language mediation in associative-learning tasks (Montague et al., 1966; Prytulak, 1971; see also Healy et al., 1993).

\section{Repetition}

Imaginal and verbal mediation are varieties of elaborative processing that create new associations between the items to be remembered (Rohwer, 1973). Repetition (either overt or covert) can be regarded as a form of mediation, in that it demands the recognition and labeling of the items in the pair (cf. Adams, Thorsheim, \& McIntyre, 1969; Flavell, 1970), and it appears to be important in learning new vocabulary (Ellis \& Beaton, 1993). It is, however, an inherently nonelaborative form of processing (Yuille, 1973). Indeed, most researchers since Reed (1918a) have not differentiated between repetition and other "mechanical" or nonelaborative processing in pairedassociate learning. Nevertheless, C. J. Martin, Boersma, and Cox (1965) identified repetition or rote rehearsal as a distinct type of associative strategy.

The present experiment found that, in the pairedassociate learning of noun pairs, repetition was reported as a mediational device only $14 \%$ of the time when the subjects were given instructions that did not specify any particular learning strategy. Not surprisingly, it was reported even less often when the subjects were given instructions to use mental imagery. Its effectiveness was much poorer than that of elaborative techniques, such as imaginal or verbal mediators, but it was far from negligible and certainly superior to the consequences of failing to use any mediator at all.

These findings are wholly consistent with those of previous studies that have used randomly assigned pairs of common concrete words (Hulicka \& Grossman, 1967; Hulicka et al., 1967; Paivio, Smythe, \& Yuille, 1968; Paivio \& Yuille, 1967, 1969). Although the effectiveness of repetition as a spontaneous mediator was quite appreciable, explicit instructions to employ it as a deliberate strategy do not lead to any increase in the overall level of performance with such materials (Paivio \& Yuille, 1969; Rimm et al., 1969; Rohwer \& Bean, 1973). Moreover, Paivio and Yuille (1969) found that even subjects who were given instructions to use repetition tended to abandon this strategy after the first trial.
Reports of the use of repetition in paired-associate learning seem to be more common (accounting for up to one third of all mediator reports) when the items to be remembered are either abstract or meaningless (Adams \& Montague, 1967; Montague \& Wearing, 1967; Paivio, Smythe, \& Yuille, 1968; Paivio \& Yuille, 1967). In the present experiment, repetition was more likely to be reported on pairs of nouns that other subjects rated as less related or associated to one another and as less imageable, in the sense that they did not easily arouse images in which the things described by the two words were interacting in some way. The four pairs of words that were the most likely to generate reports of repetition under standard instructions in the present experiment were cattle-book (25\%), flood-queen (24\%), wheat-star $(21 \%)$, and money-corn $(20 \%)$.

Within the "levels of processing" framework that was devised by Craik and Lockhart (1972), covert or overt repetition was regarded as a variety of "Type I processing" or maintenance rehearsal that did not serve to enhance long-term retention. While it is true that maintenance rehearsal does not increase performance in free recall (e.g., Craik \& Watkins, 1973; Mazuryk \& Lockhart, 1974; Shaughnessy, 1981), it does enhance recognition memory both for individual words (Woodward, Bjork, \& Jongeward, 1973) and for specific pairs of words (Nairne, 1983). This indicates that repetition strengthens the representations in long-term memory of the materials being rehearsed (and, in particular, the associative links among their components) without providing associative links to other materials of the kind that would facilitate free recall. This account is consistent with the results of the present study, insofar as the use of repetition was associated with a moderate level of retention when the subjects learned pairs of nouns and were cued with one of the nouns within each pair to recall the other noun.

\section{Other Mediators}

Paivio and Yuille (1967) added "repetition" and "some other device" to the response alternatives included in the postlearning questionnaire that had been devised by Paivio et al. (1966). In addition, Yuille and Paivio (1968) found that both categories were required when independent judges classified brief descriptions of the mediators that the subjects had used. Nevertheless, Paivio and his colleagues did not analyze data obtained using the category of other mediators because it was rarely used and deemed to be of little theoretical interest (see also Paivio, Smythe, \& Yuille, 1968). The only data that they provided were that, in one experiment, the overall reported use of other mediators was 3.7\% (Paivio \& Yuille, 1969). Hulicka and Grossman (1967) and Hulicka et al. (1967) employed a similar category of idiosyncratic techniques, and they obtained figures of $5 \%$ and $2 \%$, respectively, in samples of high-school students.

In the present study, this category was reported rather more than $5 \%$ of the time under standard instructions 
and less than $2 \%$ of the time under imagery instructions. In a few cases, the subjects had jotted comments on the postlearning questionnaire beside the items, and these suggested that the mediators in question were usually associations based on idiosyncratic personal experiences. The four pairs of words that were the most likely to generate reports of other mediators under standard instructions were dollar-bar (9\%), sea-lake (9\%), child-diamond $(9 \%)$, and sugar-body (8\%). These were also among the most likely pairs to generate reports of verbal mediators (see above). However, across all 40 pairs of nouns, the incidence of other mediators was essentially independent of both the imageability and the relatedness of each pair, and this is consistent with the idea that these mediators are largely idiosyncratic in nature.

Nonetheless, the effectiveness of such mediators was remarkably high. Indeed, there was no significant difference between the effectiveness of verbal mediators and the effectiveness of other mediators. Moreover, the effectiveness of other mediators remained high even when the subjects had been given instructions to use mental imagery. Very similar results were found with samples of high-school students by Hulicka and Grossman (1967) and Hulicka et al. (1967). L. D. Groninger and L. K. Groninger $(1984,1988)$ found that instructions to generate autobiographical episodes as mediators enhanced the retention of individual words, provided that the episodes generated at the time of encoding were reinstated during the subsequent retention test.

\section{No Mediators}

As mentioned earlier, most researchers have not differentiated between the complete absence of any mediating device and the use of rote repetition or other forms of nonelaborative processing in paired-associate learning, and this was true even of the study by Paivio et al. (1966). In other experiments, Paivio and his colleagues included a separate "none" category but provided no data concerning how often it had been reported.

Other researchers found that subjects failed to report any mediators between $2 \%$ and $12 \%$ of the time (Hulicka \& Grossman, 1967; Hulicka et al., 1967; C. J. Martin, Boersma, \& Cox, 1965; Montague \& Wearing, 1967). These figures seem to depend on the meaningfulness of the pairs, the rate at which they are presented, and the instructions that have been given to the subjects. In the present study, the subjects reported no mediators for more than $11 \%$ of the pairs under standard instructions but fewer than $5 \%$ of the pairs under imagery instructions. As in the case of reports of the use of repetition, reports of no mediators were more likely on pairs that other subjects rated as less related or associated to one another and as less imageable. The pairs that were most likely to generate reports of no mediators under standard instructions were cattle-book (20\%), money-corn (20\%), pupilsteam $(19 \%)$, and bowl-library (18\%). Two of these pairs were also among the most likely to produce reports of the use of repetition (see above).
Effectiveness in the case of this category refers to the likelihood that a pair is correctly recalled, given that the subject fails to report any mediator. Hulicka and Grossman (1967), Hulicka et al. (1967), and Paivio, Smythe, and Yuille (1968) obtained figures of between $20 \%$ and $35 \%$ for student samples. In each case, the level of recall was appreciably lower than that obtained with either imaginal or verbal mediators and lower than that obtained with rote repetition (see also C. J. Martin, Boersma, \& Cox, 1965; Montague \& Wearing, 1967). In the present experiment, the corresponding figures were lower (between $6 \%$ and $8 \%$ ), but the reason for this discrepancy is unclear.

It is not surprising that performance in associative learning should be better when subjects report elaborative mediation than when they report nonelaborative mediation. It is not surprising that performance should be better when subjects report the use of repetition than when they report no mediational strategies at all. What is surprising is that performance in these latter circumstances should be nonzero. One possibility, of course, is that mediational strategies may simply be forgotten between the recall test and the collection of mediator reports; this will be considered in a later section. Prytulak (1971) discussed four other possible explanations for subjects' failure to report mediators when items had been remembered:

1. One explanation is that at least some mediators are unconscious. This was originally put forward by Bugelski and Scharlock (1952) on the basis of findings obtained using the $\mathrm{A}-\mathrm{B}, \mathrm{B}-\mathrm{C}, \mathrm{A}-\mathrm{C}$ transfer paradigm. Although the learning of $A-C$ pairs was facilitated by having previously learned the $\mathrm{A}-\mathrm{B}$ and $\mathrm{B}-\mathrm{C}$ pairs, none of the subjects reported using $\mathrm{B}$ items as mediators in learning the $\mathrm{A}-\mathrm{C}$ pairs. Similar results were found by Russell and Storms (1955) with an $\mathrm{A}-\mathrm{B}, \mathrm{A}-\mathrm{C}$ paradigm when the B and C items were associatively linked. However, in neither study were the subjects requested to give the mediators that they had used. Subsequent research demonstrated that both paradigms permitted a variety of associative links other than the mediator that had been experimentally furnished and that these were duly reported if they improved recall (Adams \& Montague, 1967; Barnes \& Underwood, 1959; Dean \& R. B. Martin, 1966; R. B. Martin \& Dean, 1964). Conversely, subjects who remain wholly unaware of any relationship between successive lists in a transfer paradigm show no facilitation (Horton, 1964). Thus, there is no evidence for unconscious or "implicit" mediation in paired-associate learning.

2. Another possibility is that at least some mediators are conscious but are not disclosed because they are personal, sexual, or aberrant in nature. This explanation is presumably irrelevant when (as in the present study) the subjects are instructed not to divulge the mediators themselves but only to assign them to different categories. Moreover, the incidence of "none" responses in the present study fell within the range of values obtained in previous experiments in which subjects gave more discur- 
sive accounts of their mediators. In short, there is no evidence that subjects are inhibited in declaring their mediators even in the latter cases.

3. A different explanation is that mediators may be important in the early stages of learning but that, with extended practice, retrieval becomes more automatic and less dependent on the use of mediational strategies. Several studies have found that the reported use of elaborative mediators (and perhaps repetition, too) increases over trials during the learning of paired associates (Adams \& McIntyre, 1967; Kiess \& Montague, 1965; Paivio \& Yuille, 1969; Runquist \& Farley, 1964). However, once the materials have been learned, the reported use of elaborative mediators then declines with overlearning (Barnes \& Underwood, 1959; Dean \& R. B. Martin, 1966; Reed, 1918b; see also Crutcher, 1992; Healy et al., 1993). The consequence is that the function relating mediator use to trials has an inverted-U shape, reaching a maximum when the level of performance approaches $100 \%$ (Adams \& McIntyre, 1967). However, this does not explain why successful recall might occur in the absence of reported mediators when the materials are presented for a single acquisition trial, as in the present study and in those reported by Hulicka and Grossman (1967) and Hulicka et al. (1967).

4. The final explanation considered by Prytulak (1971) was that learning in the absence of either elaborative mediators or covert rehearsal consisted simply in "rote processes." Prytulak did not try to explicate this notion, except to suggest that rote processes presumably consisted in the "gradual erosion of association pathways" among the elements of a stimulus (p. 1). Underwood and Schulz (1960) had raised the question of how learning could occur in the absence of an associative aid, which they described as "raw" learning (p. 302). However, they acknowledged that they were at a loss to understand the processes that might be involved in this kind of learning. Underwood (1964) similarly argued that learning in the absence of reported mediators arose when associations were developed by the "mere contiguity" of stimulus and response terms (p. 69). This is the only one of Prytulak's accounts that is consistent with the findings of the present experiment, but it does depend on the wholly mysterious notion of "rote processes."

\section{POSSIBLE PROBLEMS WITH MEDIATOR REPORTS}

\section{Mediator Reports as Introspective Evidence}

Some writers have objected to the use of mediator reports and other first-person accounts of cognitive processes. The first objection is that mediator reports are purely introspective evidence. On this ground alone, it has been proposed that mediator reports have no scientific value since their accuracy and validity are open to question (McDaniel, 1988; Runquist \& Farley, 1964). Nisbett and Wilson (1977) argued more specifically that many types of cognitive process were in principle not accessible to conscious introspection and that any verbal reports would consequently be based on subjective and implicit theories of the processes involved. However, Nisbett and Wilson deliberately excluded from their criticisms introspective judgments concerning thoughts, feelings, and sensations. Ericsson and Simon (1980; 1984, pp. 25$30)$ suggested that the latter range of mental episodes encompassed cognitive processes that were the object of focal attention in short-term memory, and this would certainly seem to include reports of the use of mediators in associative learning.

It is feasible, in some instances, to validate mediator reports against behavioral data (cf. Ericsson \& Crutcher, 1991). In experiments on free recall, for example, it is possible to validate reports concerning the use of organizational schemata against patterns or clusters seen in the recall protocols (see Marton, 1970; Roberts, 1968). In associative learning, one might require the subjects to describe their verbal mediators at the time of presentation and compare these accounts with reports given at the time of recall (see below). However, as mentioned earlier, it is possible that instructing subjects to externalize their mediators as written phrases or sentences in this manner fundamentally changes the nature of the task. In these cases, it may be necessary to conclude that selfreports provide the only legitimate way of ascribing cognitive states (Quinton, 1973, p. 328).

\section{Mediator Reports as Retrospective Evidence}

A second objection that has been put forward is that mediator reports are retrospective evidence-that is, mediator reports provide accounts of cognitive processing that are invalid (or, at the very least, unreliable) because the time lag from the original occurrence of the relevant cognitive events reduces the accuracy of the reports. On the one hand, there is the possibility that the subjects forget that they have used a particular mediator at the original time of encoding (L. D. Groninger \& L. K. Groninger, 1984; Murdock, 1997). On the other hand, there is the possibility that the lack of accurate information causes the subjects to rely on inferences and reconstructions derived from their own implicit causal theories of the cognitive processes involved (see Ericsson \& Simon, 1980; 1984, pp. 19-20; Nisbett \& Wilson, 1977; White, 1989). However, Ericsson and Simon (1984, p. 19) argued that reports collected soon after the completion of the task in question would usually yield accurate accounts of cognitive processing.

In principle, mediator reports do not have to be obtained by means of questionnaires administered after the (final) retention test: They could, instead, be collected during the original presentation of the materials to be remembered, between their presentation and their recall, or at the time of their recall. Consider the first of these possibilities: Unfortunately, reports obtained during presentation may significantly alter the subjects' cognitive 
activities. Ericsson and Simon (1984, pp. 78-107; 1993, pp. xvii-xxxii) argued that obtaining concurrent reports affected ongoing processing only if subjects were called on to explain their thought processes or motives. However, there is evidence that concurrent reports may impede performance in certain problem-solving tasks, especially those that demand creative insight (Hoc \& Leplat, 1983; Schooler, Ohlsson, \& Brooks, 1993). It could be argued that associative learning demands insight processes, in that the problem of remembering a specific paired associate can be solved by discovering an effective mediator (Flavell, 1970; Reed, 1918c; Rock, 1957). On this basis, one might expect that obtaining concurrent reports may impair the discovery of elaborative mediators in associative learning.

At the same time, instructing subjects to report mediators during the presentation of the materials to be remembered is likely to prompt them to use mediators more than they might do in the absence of such instructions. A similar point applies when the subjects supply retrospective reports but are given advance warning of this requirement, either by means of explicit instructions (e.g., Reed, 1918a) or by having been asked to report their mediators on earlier trials or learning tasks (e.g., Kiess $\&$ Montague, 1965). Using a retroactive-interference (A-B, A-C) paradigm, Adams and Montague (1967) observed in pilot studies that obtaining mediator reports after subjects had learned the first (A-B) list appeared to enhance the number of mediators that they subsequently reported on the second $(\mathrm{A}-\mathrm{C})$ list; consequently, in their main experiment, they explicitly encouraged their subjects to generate elaborative mediators on both lists. These considerations indicate that it is not possible to obtain concurrent reports in associative learning from genuinely uninstructed subjects.

The next possibility - that of collecting mediator reports between the presentation and recall of the materials to be remembered - is problematic, because prompting the subjects with the original items would constitute an additional learning trial. It is indeed known that the administration of a postlearning questionnaire enhances the subsequent retention of the pairs on which mediator reports have been obtained (Boersma, Conklin, \& Carlson, 1966; Ericsson \& Simon, 1993, pp. xx-xxi). Stoff and Eagle (1971) instead asked a general question concerning the strategies that their subjects had adopted in a free-recall task. However, Ericsson and Simon (1980; 1984 , pp. $23,149-152 ; 1993$, p. xlix) suggested that subjects might have difficulty in responding to queries at such a general level and, therefore, might well resort to inferences and speculation when generating their verbal reports.

Finally, it is possible to obtain reports of associative mediators at the time of the recall by cuing subjects only with the stimulus members of the paired associates (e.g., Montague \& Wearing, 1967; Paivio, Smythe, \& Yuille,
1968; Paivio \& Yuille, 1969). This procedure generates results that are similar to those obtained using postlearning questionnaires containing the intact paired associates. However, there is a practical difficulty that subjects might be misled into believing that they were to generate mediator reports only for those pairs in which they were able to recall the response terms. Indeed, in a study by Turner (1978), mediator reports were sought only for pairs that had been correctly recalled; these reports are unlikely to be a reliable indicator of the subjects' overall use of different strategies (cf. also Ellis \& Beaton, 1993). More fundamentally, Hoc and Leplat (1983) demonstrated that accurate first-person accounts of cognitive processing would be obtained only through questions that served to reinstate the context in which the processing had occurred, which, in this case, demands the presentation of the original intact pairs of items.

Nevertheless, experiments that have obtained mediator reports at an earlier stage in the learning process have provided evidence regarding the reliability of reports obtained by means of postlearning questionnaires. Following one presentation of 96 pairs of nonsense syllables, Montague et al. (1966) found that $74 \%$ of the mediators that had been reported during their presentation either were different or had been completely forgotten when further reports were obtained during a recall test the following day. However, other researchers found that the vast majority of mediators that were reported following the acquisition phase were accurately retained up to a week later (Adams \& McIntyre, 1967; Boersma et al., 1966; cf. also L. D. Groninger, D. H. Groninger, \& Stiens, 1995; L. D. Groninger \& L. K. Groninger, 1988). There is, certainly, no evidence that accurate mediator reports will not be obtained when subjects are questioned immediately after the presentation and recall of the material to be remembered, as in the present study.

However, this is not to argue that all retrospective reports will be equally informative. In some studies, subjects were asked fairly general questions about the kinds of strategies that they had used in a learning task (e.g., Eagle, 1967; Eagle \& Leiter, 1964; Hasher et al., 1976; Stoff \& Eagle, 1971; Weinstein, Underwood, Wicker, \& Cubberly, 1979) or how often they had used particular strategies (e.g., Anderson \& Kulhavy, 1972; McDaniel \& Kearney, 1984; Shaughnessy, 1981) instead of specific questions about how they had set about learning the individual items. As mentioned earlier, Ericsson and Simon $(1980,1984,1993)$ argued that subjects might well have difficulty in responding at such a general level and thus would resort to speculation and inferences in generating their verbal reports (cf. also Weinstein et al., 1979). Cantor, Andreassen, and Waters (1985) demonstrated that more accurate accounts of cognitive processing would be obtained by specific questions reflecting the subjects' ongoing cognitive activities. Indeed, citing the very procedure used in the present study, Ericsson 
and Simon (1993) argued that "more valid information is attained by cuing subjects with specific items from the experiment" (p. xlix).

\section{Mediator Reports as Correlational Evidence}

A third objection that has been put forward is that mediator reports are correlational evidence. Contrary to the assertion made by Reed (1918a) that "these facts establish a causal relation between the rate of learning and forgetting, on the one hand, and associative aids, on the other hand" (p. 137), the observation of merely a correlation between mediator reports and recall performance leaves the underlying causal relationship uncertain (Paivio, 1971, p. 359). One particular criticism of retrospective reports is that the subjects might simply report the use of mediators on the items that they remembered either to rationalize their performance or to comply with the apparent aims of the experimenter (e.g., McDougall \& Velmans, 1993; Runquist \& Farley, 1964; Underwood \& Schulz, 1960, p. 298).

This analysis would certainly explain why subjects are more likely to report elaborative mediators in the case of pairs that have been correctly recalled, why they report increasing numbers of mediators over successive trials, and why they are more likely to report imaginal mediators if they have been given imagery instructions. It would also explain why different distributions of mediator reports are obtained after learning concrete and abstract pairs if it is assumed that subjects are cued by the concreteness of the materials in completing postlearning questionnaires (Paivio, 1971, p. 359; Paivio et al., 1966). However, it is difficult to see how such an account could explain why recall performance can be predicted by mediators previously reported at presentation (Adams et al., 1969), why the latency for correctly recalling pairs for which mediators are reported is longer than that for recalling pairs for which no mediators are reported (Reed, 1918 b), or why pairs are virtually never remembered if a mediator reported at presentation has been forgotten by the time of recall (see Bellezza \& Poplawsky, 1974; Healy et al., 1993; Montague et al., 1966; Yuille, 1973).

Moreover, it is possible to devise situations in which the reported use of mediators does not just covary with recall performance. Schulz and Lovelace (1964) found that the prior acquisition of associative mediators did not enhance performance if the time allowed for recall was limited to $2 \mathrm{sec} /$ pair. Their subjects reported that they were aware of the mediating associations but had been unable to utilize these within the limited time available at recall. Similarly, Schwartz (1969) found that instructions to use verbal mediators increased the number of mediators that were reported in postlearning questionnaires but did not facilitate recall performance if the time allowed for recall was limited to $2 \mathrm{sec} /$ pair. These findings speak against the idea that mediator reports are simply an epiphenomenon determined by the actual or per- ceived level of recall performance (though they do not imply that mediator reports are never epiphenomenal).

Montague et al. (1966) showed that extending the presentation time of each pair increased the number of reported mediators and enhanced recall performance (see also Wood \& Bolt, 1968), although it did not increase the conditional probability of correct recall, given that a mediator had been reported. Taken together, these results indicate that the availability of associative mediators is determined in part by the opportunity to engage in elaborative processing at the time of presentation, but that their effectiveness is determined by the opportunity to engage in elaborative processing at the time of recall. Indeed, the efficacy of associative mediators depends on their successful reinstatement during the recall test itself (L. D. Groninger \& L. K. Groninger, 1982).

This last point obviously instantiates the general principle that the likelihood of correct recall is optimized when the conditions at retrieval match the information encoded at the time of presentation. This "encoding specificity principle" was first formulated in terms of the explicit cues and other physical context present at the time of learning (see Tulving \& Thomson, 1973). In contrast, associative mediators constitute an internal or mental context generated during the presentation of the materials to be remembered. If this mental context can be reconstructed at the time of the recall test, then it serves as an effective cue for the retrieval of the appropriate information (Bellezza, 1986; L. D. Groninger \& L. K. Groninger, 1984).

It could be suggested that the most convincing evidence for some sort of causal relation between mediator reports and recall performance derives from evaluating the effects of particular instructional sets. Instructing subjects to employ the same mediational devices that they themselves would spontaneously report in the absence of specific instructions gives rise to substantial improvements in objective performance. In the experiment that was described here, the subjects who were given standard learning instructions often reported the use of mental imagery to learn pairs of common concrete nouns, and this was associated with a high level of performance. However, explicit instructions to use mental imagery as an associative strategy led to an increase in the reported use of imaginal mediators, plus an increase in the level of recall performance. To the extent that the administration of imagery instructions constitutes an objective experimental manipulation of the availability of imaginal mediators, the results of this experiment and earlier experiments directly implicate the formation of elaborative mediators as a causal determinant of human memory performance (see Richardson, 1985).

It is widely assumed that the primary effect of mnemonic instructions is to enhance the availability of effective mediational strategies (Eagle, 1967; Paivio, 1971, p. 359; Richardson, 1985; Schwartz, 1969). Certainly, 
the present experiment demonstrated that the use of imaginal mediators was associated with a high level of performance and that the administration of imagery instructions increased the use of imaginal mediators. Thus, it is not surprising that imagery instructions should lead to an increase in the absolute level of retention. However, the present experiment demonstrated also that the administration of imagery instructions led to an even higher level of performance conditional on the use of mental imagery. In other words, imagery instructions serve to enhance the effectiveness of imaginal mediators as well as their availability.

It is hard to attribute the latter finding to variations in perceived demand characteristics. In principle, as mentioned earlier, the increased reporting of imaginal mediators under imagery instructions could reflect the subjects' attempts to rationalize their increased recall performance or simply to comply with the aims of the researcher, as expressed in the experimental instructions. The latter explanation would be more plausible if there was some explicit penalty attached to noncompliance. For example, Boltwood and Blick (1970) warned their subjects that, if they did not use particular mnemonic techniques as directed, "their scores would have to be discarded and this would jeopardize the entire experiment" (p. 340).

However, in the present experiment, although the subjects were being asked whether they had complied with the experimental instructions, they were also explicitly allowed to indicate that they had not been able to do so. Indeed, neither the retrospective rationalization of increased recall performance nor compliance with the perceived aims of the researcher would lead to an increase in the conditional probability of correct recall given the reporting of imaginal mediators. In short, the experimental findings of this study (increased effectiveness of imaginal mediators under imagery instructions) serve to confirm the main implications of the correlational findings (better recall performance associated with the reported use of imagery) in demonstrating the causal efficacy of imaginal mediators.

\section{CONCLUSIONS}

It is possible, both in principle and in practice, to differentiate between the availability of different types of associative mediator (the likelihood of their being used) and the effectiveness of different types of mediator (the likelihood of their use leading to successful performance; see Flavell, 1970). The administration of postlearning questionnaires after the completion of an associativelearning task is an appropriate and valid means of obtaining retrospective reports on the use of different types of mediator. Such reports can then be used to estimate the availability and effectiveness of different types of associative mediator and to assess the subjects' compliance with specific instructional sets (Bellezza, 1986).
Unfortunately, the vast majority of previous studies concerned with the efficacy of associative mediators have confounded their availability with their effectiveness by operationalizing the former in terms of particular instructional sets and the latter in terms of the resulting level of performance. Those investigations that have distinguished between the availability and the effectiveness of different types of associative mediator have involved idiosyncratic samples of material and relatively small samples of subjects. Consequently, previous research cannot be said to have settled the questions whether mediators of different types vary in their effectiveness and whether their effectiveness varies in turn under different instructional sets.

However, the results of the present investigation have confirmed and extended the findings of previous research in several respects. First, the use of mental imagery is a preferred mediational technique when learning pairs of common concrete nouns, whereas verbal mediators are commonly used in the learning of abstract or meaningless materials. Second, the use of imaginal mediators is associated with a high level of recall performance when learning pairs of common concrete nouns. Third, the vast majority of subjects comply with instructions to use mental imagery when learning pairs of common concrete nouns. This both increases the availability of effective associative devices and gives rise to substantial improvements in recall performance. Finally, however, instructions to use mental imagery also enhance the effectiveness of the imaginal mediators that are used, perhaps by promoting the interactive encoding of the materials to be remembered.

Associative processes are, of course, involved in a variety of research paradigms in addition to paired-associate learning, such as free recall (Eagle, 1967; Stoff \& Eagle, 1971), serial recall (Roediger, 1980), and even the BrownPeterson task (Adams et al., 1969; L. D. Groninger, 1966). They can also be promoted by a variety of mnemonic techniques apart from simple linking imagery, such as the method of loci, the peg-word method, and the story mnemonic. In the latter contexts, it is more difficult to monitor separately the use and the effectiveness of associative mediators, and few researchers have even attempted to do so (Bellezza, 1986). Nevertheless, the findings of this investigation testify to the value of mental imagery in associative mediation, and they support the continued investigation of the practical utility of imagery mnemonics in education and therapeutic settings (Herrmann \& Searleman, 1990).

\section{REFERENCES}

AdAms, J. A., \& MCInTYRE, J. S. (1967). Natural language mediation and all-or-none learning. Canadian Journal of Psychology, 21, 436-449.

Adams, J. A., \& Montagle, W. E. (1967). Retroactive inhibition and natural language mediation. Journal of Verhal Learning \& Verbal $B e^{\prime}-$ havior, 6, 528-535. 
Adams, J. A., Thorsheim, H. 1., \& McIntyre, J. S. (1969). Item length, acoustic similarity, and natural language mediation as variables in short-term memory. Journal of Experimental Psychology, 80, 39-46.

ANDERSON, J. R., \& BOWER, G. H. (1973). Human associative memory. Washington, DC: Winston

Anderson, R. C., \& Kulhavy, R. W. (1972). Imagery and prose learning. Journal of Educational Psychology, 53, 242-243.

BarNES, J. M., \& UNDERWOOD, B. J. (1959). "Fate" of first-list associations in transfer theory. Journal of Experimental Psychology, 58, 97105.

BEGG, I. (1978). Imagery and organization in memory: Instructional effects. Memory \& Cognition, 6, 174-183.

BeLlezzA, F. S. (1986). Mental cues and verbal reports in learning. In G. H. Bower (Ed.), The psychology of learning and motivation: Advances in research and theory (Vol. 20, pp. 237-273). Orlando, FL: Academic Press.

Bellezza, F. S., \& Poplawsky, A. J. (1974). The function of one-word mediators in the recall of word pairs. Memory \& Cognition, 2, 447-452.

Bobrow, S. A., \& Bower, G. H. (1969). Comprehension and recall of sentences. Journal of Experimental Psychology, 80, 455-461.

Boersma, F. J., Conklin, R. C., \& Carlson, J. E. (1966). Effects of reporting associative strategies on the retention of paired-associates. Psychonomic Science, 5, 463-464.

BolTwood, C. E., \& BLICK, K. A. (1970). The delineation and application of three mnemonic techniques. Psychonomic Science, 20, 339-341.

BOWER, G. H. (1970). Imagery as a relational organizer in associative learning. Journal of Verbal Learning \& Verbal Behavior, 9, 529-533.

BowER, G. H. (1972). Mental imagery and associative learning. In L. W Gregg (Ed.), Cognition in learning and memory (pp. 51-88). New York: Wiley.

BoWER, G. H., \& WINZENZ, D. (1970). Comparison of associative learning strategies. Psychonomic Science, 20, 119-120.

BUGELSKI, B. R. (1962). Presentation time, total time, and mediation in paired-associate learning. Journal of Experimental Psychology, $\mathbf{6 3}$ 409-412.

BUgelSKI, B. R., \& SCHARLOCK, D. P. (1952). An experimental demonstration of unconscious mediated association. Journal of Experimental Psychology, 44, 334-338.

Cantor, D. S., ANDreassen, C., \& Waters, H. S. (1985). Organization in visual episodic memory: Relationships between verbalized knowledge, strategy use, and performance. Journal of Experimental Child Psychology, 40, 218-232.

CLARK, H. H. (1973). The language-as-fixed-effect fallacy: A critique of language statistics in psychological research. Journal of Verbal Learning \& Verbal Behavior, 12, 335-359.

Clark, L. L., Lansford, T. G., \& Dallenbach, K. M. (1960). Repetition and associative learning. American Journal of Psychology, 73, $22-40$

Coleman, E. B. (1979). Generalization effects vs. random effects: Is $\sigma_{\mathrm{TL}}^{2}$ a source of Type 1 or Type 2 error? Journal of Verbal Learning \& Verbal Behavior, 18. 243-256.

Craik, F. I. M., \& LockharT, R. S. (1972). Levels of processing: A framework for memory research. Journal of Verbal Learning \& Verbal Behavior, 11, 671-684.

Craik, F. I. M., \& WATKINS, M. J. (1973). The role of rehearsal in shortterm memory. Journal of Verbal Learning \& Verbal Behavior, 12, 599-607.

CROWDER, R. G. (1993). Systems and principles in memory theory: Another critique of pure memory. In A. F. Collins, S. E. Gathercole, M. A. Conway, \& P. E. Morris (Eds.), Theories of memory (pp. 139161). Hove, U.K.: Erlbaum.

CRUTCHER, R. J. (1992). The effects of practice on retrieval of foreign vocabulary learned using the keyword method. Dissertation Abstracts International, 53, $3187 \mathrm{~B}$.

DALLETT, K. M. (1964). Implicit mediators in paired-associate learning. Journal of Verbal Learning \& Verbal Behavior, 3, 209-214.

DEAN, S. J., \& MARTIN, R. B. (1966). Reported mediation as a function of degree of learning. Psychonomic Science, 4, 231-232.
EAGLE, M. N. (1967). The effect of learning strategies upon free recall. American Journal of Psychology, 80, 421-425.

EAGLE, M. [N.], \& LEITER, E. (1964). Recall and recognition in intentional and incidental learning. Journal of Experimental Psychology, 68, 58-63.

Ellis, N., \& BEATON, A. (1993). Factors affecting the learning of foreign language vocabulary: Imagery keyword mediators and phonological short-term memory. Quarterly Journal of Experimental Psychology, 46A, 533-558.

ERICsSON, K. A., \& CrUTCHER, R. J. (1991). Introspection and verbal reports on cognitive processes--Two approaches to the study of thinking: A response to Howe. New Ideas in Psychology, 9, 57-71.

ERICsson, K. A., \& Simon, H. A. (1980). Verbal reports as data. Psychological Review, 87, 215-251.

Ericsson, K. A., \& Simon, H. A. (1984). Protocol analysis: Verbal reports as data. Cambridge, MA: MIT Press.

Ericsson, K. A., \& Simon, H. A. (1993). Protocol analysis: Verbal reports as data (rev. ed.). Cambridge, MA: MIT Press.

FLAVELL, J. H. (1970). Developmental studies of mediated memory. In H. W. Reese \& L. P. Lipsitt (Eds.), Advances in child development and behavior (Vol. 5, pp. 181-211). New York: Academic Press.

GroniNGER, L. D. (1966). Natural language mediation and covert rehearsal in short-term memory. Psychonomic Science, 5, 135-136.

Groninger, L. D., Groninger, D. H., \& Stiens, J. (1995). Learning the names of people: The role of image mediators. Memory, 3, 147-167.

Groninger, L. D., \& Groninger, L. K. (1982). Function of images in the encoding-retrieval process. Journal of Experimental Psychology: Learning, Memory, \& Cognition, 8, 353-358.

Groninger, L. D., \& Groninger, L. K. (1984). Autobiographical memories: Their relation to images, definitions, and word recognition. Journal of Experimental Psychology: Learning, Memory, \& Cognition, 10, 745-755.

Groninger, L. D., \& Groninger, L. K. (1988). Autobiographical episodes as mediators in the recall of words. American Journal of Psychology, 101, 515-538.

HASHER, L., RIEBMAN, B., \& WREN, F. (1976). Imagery and the retention of free-recall learning. Journal of Experimental Psychology: Human Learning \& Memory, 2, 172-181.

healy, A. F., Clawson, D. M., McNamara, D. S., Marmie, W. R., SChNeider, V. I., Rickard, T. C., Crutcher, R. J., King, C. L., ERICsSON, K. A., \& Bourne, L. E., Jr. (1993). The long-term retention of knowledge and skills. In D. L. Medin (Ed.), The psychology of learning and motivation: Advances in research and theory (Vol. 30, pp. 135164). San Diego, CA: Academic Press.

Herrmann, D. J., \& Searleman, A. (1990). The new multimodal approach to memory improvement. In G. H. Bower (Ed.). The psychology of learning and motivation: Advances in research and theory (Vol. 26, pp. 175-205). San Diego, CA: Academic Press.

HoC, J. M., \& LEPLAT, J. (1983). Evaluation of different modalities of verbalization in a sorting task. International Journal of Man-Machine Studies, 18, 283-306.

Horton, D. L. (1964). The effects of meaningfulness, awareness, and type of design in verbal mediation. Journal of Verbal Learning \& Verbal Behavior, 3, 187-194.

Hulicka, I. M., \& Grossman, J. L. (1967). Age-group comparisons for the use of mediators in paired-associate learning. Journal of Gerontology, 22, 46-51.

Hulicka, I. M., Sterns, H., \& Grossman, J. (1967). Age-group comparisons of paired-associate learning as a function of paced and self-paced association and response times. Journal of Gerontology, 22, 274-280.

JANSSEN, W. H. (1976a). On the nature of the mental image. Soesterberg, The Netherlands: Institute for Perception TNO.

JANSSEN, W. H. (1976b). Selective interference during the retrieval of visual images. Quarterly Journal of Experimental Psychology, 28, 535-539.

JANSSEN, W. H. (1976c). Selective interference in paired-associate and free recall learning: Messing up the image. Acta Psychologica, 40, 35-48.

Jensen, A. R., \& Rohwer, W. D., JR. (1963). Verbal mediation in paired-associate and serial learning. Journal of Verbal Learning \& Verbal Behavior, 1, 346-352. 
Kiess, H. O., \& Montague, W. E. (1965). Natural language mediators in paired associate learning. Psychonomic Science, 3, 549-550.

KinLSTROM, J. F. (1996). Memory research: The convergence of theory and practice. In D. J. Herrmann, C. McEvoy, C. Hertzog, P. Hertel, \& M. K. Johnson (Eds.), Basic and applied memory research: Vol. I. Theory in context (pp. 5-25). Mahwah, NJ: Erlbaum.

KossLYN, S. M. (1994). Image and brain: The resolution of the imagery debate. Cambridge, MA: MIT Press.

Marquer, J., \& Pereira, M. (1990). Reaction times in the study of strategies in sentence-picture verification: A reconsideration. Quarterly Journal of Experimental Psychology, 42A, 147-168.

MARSCHARK, M., \& CORNOLDI, C. (1991). Imagery and verbal memory. In C. Cornoldi \& M. A. McDaniel (Eds.), Imagery and cognition (pp. 133-182). New York: Springer-Verlag.

MARSCHARK, M., \& HUNT, R. R. (1989). A reexamination of the role of imagery in learning and memory. Journal of Experimental Psychology: Learning, Memory, \& Cognition, 15, 710-720.

Marschark, M., Richman, C. L., Yuille, J. C., \& Hunt, R. R. (1987). The role of imagery in memory: On shared and distinctive information. Psychological Bulletin, 102, 28-41.

Martin, C. J., Boersma, F. J., \& Cox, D. L. (1965). A classification of associative strategies in paired-associate learning. Psychonomic Science, 3, 455-456.

Martin, C. J., Cox, D. L., \& Boersma, F. J. (1965). The role of associative strategies in the acquisition of P-A material: An alternative approach to meaningfulness. Psychonomic Science, 3, 463-464.

MarTIN, R. B., \& DEAN, S. J. (1964). Implicit and explicit mediation in paired-associate learning. Journal of Experimental Psychology, 68, $21-27$

MarTon, F. (1970). Structural dynamics of learning. Stockholm: Almqvist \& Wiksell.

MAZURYK, G. F., \& Lockhart, R. S. (1974). Negative recency and levels of processing in free recall. Canadian Journal of Psychology, 28, 114-123.

MCDANIEL, M. A. (1988). Empirical approaches $t \Omega$ a functional analysis of imagery and cognition. In M. Denis, J. Eugelkamp, \& J. T. E. Richardson (Eds.), Cognitive and neuropsychological approaches to mental imagery (pp. 281-291). Dordrecht: Martinus Nijhoff.

McDaniel, M. A., \& Kearney, E. M. (1984). Optimal learning strategies and their spontaneous use: The importance of task-appropriate processing. Memory \& Cognition, 12,361-373.

McDougall, S., \& Vel.mans, M. (1993). Encoding strategy dynamics When relationships between words determine strategy use. British Journal of Psychology, 84, 227-248.

Montague, W. E., Adams, J. A., \& Kiess, H. O. (1966). Forgetting and natural language mediation. Journal of Experimental Psychology, 72 , 829-833.

Montague, W. E., \& Wearing, A. J. (1967). The complexity of natural language mediators and its relation to paired-associate learning. $P s y$ chonomic Science, 7, 135-136.

Morris, P. E., \& REID, R. L. (1975). The role of stimulus and pair imagery in paired-associate learning. British Journal of Psychology, 66 , 153-156

Murdock, B. B. (1997). Context and mediators in a theory of distributed associative memory (TODAM2). Psychological Review, 104, $839-862$

NAIRNE, J. S. (1983). Associative processing during rote rehearsal. Journal of Experimental Psychology: Learning. Memory: \& Cogni. tion, 9, 3-20

NISBETT, R. E., \& WiL.SON, T. D. (1977). Telling more than we can know: Verbal reports on mental processes. Psychological Review, 84, 231-259.

PAIvio, A. (1969). Mental imagery in associative learning and memory. Psychological Review, 76, 241-263.

PaIvio, A. (1971). Imagen and verbal processes. New York: Holt, Rinehart \& Winston.

Paivio, A., Clark, J. M., \& Khan, M. (1988). Effects of concreteness and semantic relatedness on composite imagery ratings and cued recall. Memory \& Cognition, 16, 422-430.

Paivio, A., \& Forн, D. (1970). Imaginal and verbal mediators and noun concreteness in paired-associate learning: The elusive interaction.
Journal of Verbal Learning \& Verbal Behavior, 9, 384-390.

Paivio, A., Smythe, P. C., \& Yullle, J. C. (1968). Imagery versus meaningfulness of nouns in paired-associate learning. Canadian Journal of Psychology, 22, 427-441.

Paivio, A., \& YuILLE, J. C. (1967). Mediation instructions and word attributes in paired-associate learning. Psychonomic Science, 8, 65-66.

Paivio, A., \& Yuille, J. C. (1969). Changes in associative strategies and paired-associate learning over trials as a function of word imagery and type of learning set. Journal of Experimental Psychology, 79, 458-463.

Paivio, A., Yuille, J. C., \& Madigan, S. A. (1968). Concreteness, imagery, and meaningfulness values for 925 nouns. Journal of Experimental Psychology Monographs, 76(1, Pt. 2).

Paivio, A., Yuille, J. C., \& Smythe, P. C. (1966). Stimulus and response abstractness, imagery, and meaningfulness, and reported mediators in paired-associate learning. Canadian Journal of Psychology, 20, 362-377.

Persensky, J. J., \& Senter, R. J. (1970). The effect of subjects' conforming to mnemonic instructions. Journal of Psychology, 74, 15-20.

PrYTULAK, L. S. (1971). Natural language mediation. Cognitive Psychology, 2, 1-56.

Quinton, A. M. (1973). The nature of things. London: Routledge \& Kegan Paul.

REED, H. B. (1918a). Associative aids: I. Their relation to learning, retention, and other associations. Psychological Review, 25, 128-155.

REED, H. B. (1918b). Associative aids: II. Their relation to practice and the transfer of training. Psychological Review, 25, 257-285.

REED, H. B. (1918c). Associative aids: III. Their relation to the theory of thought and to methodology in psychology. Psychological Review, $25,378-401$.

Richardson, J. T. E. (1978). Reported mediators and individual differences in mental imagery. Memory \& Cognition, 6, 376-378.

RICHARDSON, J. T. E. (1979). Correlations between imagery and memory across stimuli and across subjects. Bulletin of the Psychonomic Society, 14, 368-370.

RichaRdSON, J. T. E. (1980). Mental imagery and human memory. London: Macmillan

RICHARDSON, J. T. E. (1985). Converging operations and reported mediators in the investigation of mental imagery. British Journal of Psychology, 76, 205-214.

Rimm, D. C., Alexander, R. A., \& Eiles, R. R. (1969). Effects of different mediational instructions and sex of subject on paired-associate learning of concrete nouns. Psychological Reports, 25, 935-940.

ROBERTS, W. A. (1968). Alphabetic coding and individual differences in modes of organization in free-recall learning. American Journal of Psychology, 81, 433-438.

Rock, I. (1957). The role of repetition in associative learning. American Journal of Psychology, 70, 186-193.

RoEdiGer, H. L., III (1980). The effectiveness of four mnemonics in ordering recall. Journal of Experimental Psychology: Human Learning \& Memory, 6, 558-567.

ROHWER, W. D., JR. (1966). Constraint, syntax and meaning in pairedassociate learning. Journal of Verbal Learning \& Verbal Behavior, $\mathbf{5}$, 541-547.

ROHWER, W. D., JR. (1973). Elaboration and learning in childhood and adolescence. In H. W. Reese (Ed.), Advances in child development and behavior (Vol. 8, pp. 1-57). New York: Academic Press.

ROHWER, W. D., JR., \& BEAN, J. P. (1973). Sentence effects and nounpair learning: A developmental interaction during adolescence. Journal of Experimental Child Psychology, 15, 521-533.

RUNquist, W. N., \& FarLey, F. H. (1964). The use of mediators in the learning of verbal paired associates. Journal of Verhal Learning \& Verbal Behavior, 3, 280-285.

Russel., W. A., \& Storms, L. H. (1955). Implicit verbal chaining in paired-associate learning. Journal of Experimental Psichology, 49. 287-293.

SCHOOLER, J. W., OHLSSON, S., \& BROOKS, K. (1993). Thoughts beyond words: When language overshadows insight. Joumal of Experimental Psichologi: General, 122, 166-183.

SChUlZ, R. W., \& LovelACE, E. A. (1964). Mediation in verbal paired- 
associate learning: The role of temporal factors. Psychonomic Science, 1, 95-96.

SCHWARTZ, M. (1969). Instructions to use verbal mediators in pairedassociate learning. Journal of Experimental Psychology, 79, 1-5.

SHAUGHNESSY, J. J. (1981). Memory monitoring accuracy and modification of rehearsal strategies. Journal of Verbal Learning \& Verbal Behavior, 20, 216-230.

Stoff, D. M., \& EAGLE, M. N. (1971). The relationship among reported strategies, presentation rate, and verbal ability and their effects on free recall learning. Journal of Experimental Psychology, 87, 423-428.

THORNDIKE. E. L., \& LoRGE, I. (1944). The teacher's word book of 30,000 words. New York: Columbia University, Teachers College Press.

Tulving, E., \& Thomson, D. M. (1973). Encoding specificity and retrieval processes in episodic memory. Psychological Review, 80, 352373.

TURNER, R. G. (1978). Individual differences in ability to image nouns. Perceptual \& Motor Skills, 47, 423-434.

UNDERWOOD, B. J. (1964). The representativeness of rote verbal learning. In A. W. Melton (Ed.), Categories of human learning (pp. 47-78). New York: Academic Press.

UNDERWOOD, B. J., \& SCHULZ, R. W. (1960). Meaningfulness and verbal learning. Chicago: Lippincott

Weinstein, C. E., Underwood, V. L., Wicker, F. W., \& Cubberly, W. E. (1979). Cognitive learning strategies: Verbal and imaginal elaboration. In H. F. O'Neil, Jr., \& C. D. Spielberger (Eds.), Cognitive and affective learning strategies (pp. 45-75). New York: Academic Press.

White. P. A. (1989). Evidence for the use of information about internal events to improve the accuracy of causal reports. British Journal of Psychology, 80, 375-382.

WooD, G. (1967). Mnemonic systems in recall. Journal of Educational Psychology Monograph, 58(6, Whole No. 645).

WOOD, G., \& BoLT, M. (1968). Mediation and mediation time in pairedassociate learning. Journal of Experimental Psychology, 78, 15-20.

WOODWARD, A. E., JR., BJORK, R. A., \& JONGEWARD, R. H., JR. (1973). Recall and recognition as a function of primary rehearsal. Journal of Verbal Learning \& Verbal Behavior, 12, 608-617.

YARMEY, A. D., \& CSAPO, K. G. (1968). Imaginal and verbal mediation instructions and stimulus attributes in paired-associate learning. Psychological Record, 18, 191-199.

YUILLE, J. C. (1973). A detailed examination of mediation in PA learning. Memory \& Cognition, 1, 333-342.
Yuille, J. C., \& Paivio, A. (1968). Imagery and verbal mediation instructions in paired-associate learning. Journal of Experimental Psychology, 78, 436-441.

\section{APPENDIX \\ Stimulus Materials and Ratings of Imageability and Relatedness}

\begin{tabular}{ll}
\multicolumn{1}{c}{ List A } & \multicolumn{1}{c}{ List B } \\
\hline cattle-book $(3.50,1.42)$ & clock-engine $(4.94,3.75)$ \\
flood-queen $(3.25,1.33)$ & city-dress $(4.56,2.50)$ \\
tree-horse $(5.19,3.08)$ & cabin-church $(3.69,2.50)$ \\
hall-table $(5.50,4.83)$ & village-forest $(5.75,5.00)$ \\
apple-palace $(3.88,1.33)$ & water-girl $(5.69,3.08)$ \\
car-wine $(4.94,2.58)$ & gold-tower $(5.25,3.08)$ \\
dollar-bar $(4.88,3.67)$ & pipe-shoe $(2.81,2.42)$ \\
mother-nail $(4.31,1.50)$ & magazine-ship $(3.69,1.75)$ \\
seat-valley $(3.50,2.17)$ & sugar-body $(3.75,4.50)$ \\
bird-house $(6.19,5.50)$ & coin-grass $(4.19,1.75)$ \\
camp-newspaper $(3.69,2.33)$ & bowl-library $(2.88,1.25)$ \\
wheat-star $(3.31,1.42)$ & hospital-window $(5.63,5.33)$ \\
skin-factory $(3.50,2.50)$ & letter-fire $(4.63,3.00)$ \\
paper-doctor $(4.94,3.25)$ & pupil-steam $(3.44,1.83)$ \\
chair-garden $(6.38,5.83)$ & cat-building $(5.63,3.50)$ \\
boy-bottle $(4.94,3.67)$ & army-plant $(3.50,2.50)$ \\
ocean-arm $(3.44,1.33)$ & wife-river $(2.88,1.58)$ \\
money-corn $(3.56,3.33)$ & sea-lake $(5.56,6.00)$ \\
baby-woman $(6.38,6.42)$ & cell-meat $(3.94,3.75)$ \\
coffee-mountain $(4.81,3.83)$ & child-diamond $(4.50,3.42)$ \\
\hline
\end{tabular}

Note-Mean ratings of imageability (based on 16 subjects) and relatedness (based on 12 subjects) are shown in parentheses after each pair of nouns.

(Manuscript received May 28, 1997 revision accepted for publication February 2, 1998.) 